\title{
Neuroglycopaenia automatism and driving culpability
}

\begin{abstract}
Hypoglycemia unawareness is a stage of automatism in a neuroglycopaenic state of the brain for insulin treated diabetes mellitus patients. Most of the Medicolegal and legal fraternity need awareness in examining such patients when they have an accident while driving. There should be a clear guidelines for people suffering from diabetes and are on insulin and oral hypoglycemic. Diabetic patients, because of their propensity to develop hypoglycemia, are more likely to be involved in a driving accident, although only slightly more than the rest of the population. Therefore, it has been a matter of debate since the earliest days of insulin therapy whether patients on insulin therapy should be allowed to have a driving license or not. Heavy vehicle licensing should be properly evaluated on regular intervals for the safety of patients, otherspeople on the road, and the vehicle.
\end{abstract}

Volume 6 Issue I - 2018

\author{
Mohd Kaleem Khan,' Maaz Ozair ${ }^{2}$ \\ 'Assistant Professor, Department of Forensic Medicine, Aligarh \\ Muslim University, India \\ ${ }^{2}$ Senior Resident, Rajiv Gandhi Centre of Endocrinology, \\ Department of Medicine, India
}

Correspondence: Mohd Kaleem Khan, Assistant Professor, Department of Forensic Medicine, J. N. Medical College, Aligarh Muslim University, Aligarh, Uttar Pradesh, 202002, India, Tel +919997992459, Email khan4uat9@gmail.com

Received: July 27, 2017 | Published: January II, 2018

\section{Introduction}

The brain constantly requires glucose to function at an optimum level and at with a tightly regulated blood glucose level of 4-10 $\mathrm{mmol} / \mathrm{L}$.Any decrease in blood sugar level $(<72 \mathrm{mg} / \mathrm{dL}$. $)$ can hamper the proper functioning of the brain. 'Insulin dependent diabetes is one of the factors for the derangement of blood glucose level. Insulin was introduced for the treatment of diabetes long way back in 1922, but it still needs proper monitoring and tight regulation. ${ }^{2}$ Hypoglycemia generally defines the blood glucose level, which may be at a lower than certain marked level in the blood $72 \mathrm{mg} / \mathrm{dL}$. \$ It does not reflect the absolute condition of glucose supply to the brain. Symptoms of hypoglycemia can cause profuse sweating, increased system as part of the body's defense against the effect of hyperglycemia in the brain. These symptoms are collectively called as acute neuroglycopaenia. Sometimes, these symptoms pass undetected, termed as subacuteneuroglycopaenia (hypoglycemia unawareness). ${ }^{3-5}$ Individuals suffering from hypoglycemia unawareness may perform certain habitually performed tasks such as talking, walking, cooking, car driving, etc. When the patient recovers from such episodes, there is no memory of whatsoever work during that episode.There seems to be needs of comprehensive studies to evaluate the cases of hypoglycaemia unawareness and proper law to deal it.Theoretical method applied in this article was to study various reported cases of hypoglycaemia unawareness and various legal aspect applied to these cases.

\section{Neuroglycopaenia automatism}

It has been acknowledged by some courts that patients may act impulsively while they are impaired by neuroglycopaenic brain malfunction and are incapable of forming intent to commit an offense, ranging from the trivial to the most heinous. ${ }^{6}$ Hypoglycemia unawareness is not self-destructive, but may cause serious damage to surrounding people and property. During driving when this happens, a person may cause an accident and continue driving until reaching a destination or stopped by traffic police. It has been reported in the past in the UK to justify a plea of not guilty based on hypoglycemia unawareness. ${ }^{7}$ Because of their propensity to de velop hypoglycemia, diabetic patients are more likely to be involved in an accident during driving only slightly more than the rest of the population. ${ }^{8,9}$
Various indicators of neuroglycopaenic behaviour:

a. Circumstances to the development of hypoglycemia.

b. The suspect had taken insulin or hypoglycemia-producing drug at the relevant time.

c. Change in the patient's demeanour after being giving sugar.

d. Amnesia for the events

e. Motiveless and uncharacteristic behaviour.

\section{Law and neuroglycopaenia automatism}

Neuroglycopaenia automatism seems to be a grey area in which laws of most developing countries have not paid attention. A country such as India having a population of about 1.25 billion with more than 62 million (7.1percent) diabetic patients, needs separate regulation on such type of automatism. ${ }^{10}$

Characteristics that may be observed during trial in court

i. The driver suffered hypoglycemic unawareness or had some warning symptoms;

ii. Was the driver previously aware of the condition? Or,

iii. He should not have been driving at all.

In India, automation and other types of mental conditions are dealt with in the Indian Penal Code (IPC) section 84.The section of the law mentions about unsound mind and the incabality of knowing the nature of the act. ${ }^{11}$ Almost negligible reporting of hypoglycaemia unawareness cases doesn't seems depicting the real picture of such conditions but it may merely be reflecting unawareness of the condition. This hypoglycemia unawareness needs a proper attention address on all fronts, including medical, legal, political and social.

\section{Vehicle driving and neuroglycopaenia automatism}

Poor driving conditions and again heavy unautomated vehicles may cause early neuroglycopaenia and that can go undetected.Most jurisdictions have concluded that, as a matter of public policy, the 
risk is sufficiently small for insulin-treated diabetic patients to be permitted to hold a driving licenseprovided they fulfil certain criteria. More stringent conditions apply to those driving public-service or large goods vehicles. ${ }^{12}$

\section{Conclusion}

a. There needs to be proper legal and policy guidelines in for conditions of hypoglycemia unawareness and with especial attention to transportation, driving sector and fine skilled work sectors.

b. Those afflicted need to be given adequate advice when first prescribed insulin.

c. There should also be public awareness programs on such topics.

d. Medical examiners at autopsies and crime scenes should also pay attention to such subjects while examining the accident cases.

\section{Conflicts of interest}

All authors declare that they have no conflict of interest.

\section{Funding}

This research received no specific grant from any funding agency in the public, commercial or not-for-profit sectors.

\section{Acknowledgments}

None.

\section{References}

1. Effect of intensive blood-glucose control with metformin on complications in overweight patients with type 2 diabetes (UKPDS 34). UK Prospective Diabetes Study (UKPDS) Group. Lancet. 1998;352(9131):854-865.

2. Banting FG, Best CH, Collip JK, et al. Pancreatic extracts in the treatment of diabetes mellitus. CMAJ. 1922;12(3):141-146.

3. Epidemiology of severe hypoglycaemia in the diabetes control and complications trial. The DCCT Research Group. Am J Med. 1991;90(4):450-459.

4. Gerich JE, Mokan M, Veneman T, et al. Hypoglycemia unawareness. Endocr Rev. 1991;12(4):356-371.

5. Marks V, Rose FC. Hypoglycemia. 2nd ed. Blackwell, USA. 1981.

6. Marks V. Hypoglycemia; accident, violence and murder. Pract Diab Int. 2005;22(8):303-306.

7. Redelmeier DA, Kenshole AB, Ray JG. Motor vehicle crashes in diabetic patients with tight glycemic control: a population-based case control analysis. PLoSMed. 2009;6(12):1000192.

8. Lonnen KF, Powell RJ, Taylor D, et al. Road traffic accidents and diabetes: insulin use does not determine the risk. Diabet Med. 2008;25(5):578-584.

9. Cox DJ, Ford D, Gonder Frederick L, et al. Driving mishaps among individuals with type 1 diabetes. A prospective study. Diabetes Care. 2009;32(12):2177-2180.

10. Joshi SR, Parikh RM. India - diabetes capital of the world: now heading towards hypertension. J Assoc Physicians India. 2007;55:323-324.

11. Section 84 IPC. Indian Penal Code 1860. 